\title{
Significance of Nature in A Clinical Setting and Its Perceived Therapeutic Value from Patients' Perspective
}

The effect that nature can have on the development of mental health and the implications for recovery is important for understanding the impact nature has on humans, as well as delineating possible alternative venues for treating psychological problems. The present qualitative study examined how individuals understand the significance of nature in relation to their mental health and treatment. Twelve participants in residential treatment for varying nonpsychotic mental health issues were interviewed about previous and present experiences with nature and the meaning these experiences have for them in recovery. Thematic analysis resulted in the creation of two main themes: «being human in nature» which included three sub-themes "experience of nature", "effects on focus and attention", and "change and the transformative in nature", and «nature, the patient and treatment» with two sub-themes "nature as therapy" and "nature and therapy". Participants describe a feeling of coming closer to themselves, to their problems and existential meanings when in nature. In addition, they report being able to make new relational experiences with other patients, and that some experiences in nature can function as symbolic tools in therapy. The study underlines the complex interrelationships between nature and humans and points to new lines for future research.

Keywords: nature; mental health, nature-based therapy, restoration

\section{Introduction}

Non-pharmaceutical treatment in the field of mental health has been defined as a verbal arena that depends upon the abilities of patients to verbalize inner states, as well as their motivation and ability to persevere in a patient-therapist relationship (Johansen, Wang, 
Binder, \& Malt, 2014). Considering that treatment time needed to help individuals with mental health problems can be long and that the allotted time in healthcare settings is getting shorter, as well as the estimation that $30-35 \%$ of patients who receive evidencebased therapy do not experience improvement (Newnham \& Page, 2010), there is good reason to look for alternative methods that can in combination with traditional treatments facilitate recovery in a shorter time frame.

Nature is sometimes utilized with specific therapeutic purposes in mental health settings, such as being a new therapeutic space different from indoor psychotherapy (Berger \& Mcleod, 2006; Jordan, 2014; Jordan \& Marshall, 2010, Revell \& Mcleod, 2016; Revell \& Mcleod, 2017), or to engage patients in specific activities or experiences (Berman et al., 2012; Corazon, Schilhab, \& Stigsdotter, 2011; Corazon, Stigsdotter, Moeller, \& Rasmussen, 2012). The therapeutic use of nature can have various connotations and grounding theories (Stigsdotter et al., 2011). On the one hand, nature can be regarded as not having any inherent therapeutic value in and of itself, but only as it is used, as when activities are performed in a natural surrounding (Ernst, Rand, \& Stevinson, 1998; Martinsen, 2000). The therapeutic value is then related to the subsidiary effects of, for example, physical exercise or coping effects due to completing tasks and challenges. On the other hand, nature is regarded as having an inherent value that promotes health and well-being (Eikenæs, Gude, \& Hoffart, 2006; Fernee, Gabrielsen, Andersen, \& Mesel, 2015). This view is closely linked to other concepts such as ecopsychology, that views humans as an integral part of nature and seeks to reestablish the bonds that have been weakened through modernization (Madsen, 2014; Slåttå \& Madsen, 2014), and the biophilia hypothesis, which proposes that humans have an innate propensity to like and be drawn to nature and natural elements as opposed to inanimate and artificial matter (Wilson, 1984). The effects of nature are thereby not 
dependent upon being in nature, but can be manifested through being near nature or in natural surroundings. This is possibly due to a hypothesized holistic relationship between humans and nature, explained by means of evolutionary mechanisms, and is advanced to counteract the supposed artificial divide between mankind and its natural surroundings.

Attention restoration theory (ART) developed by Kaplan and Kaplan (1989) focuses on cognitive processes in restorative environments that recuperate attentional resources. The causal mechanism is based upon the idea that restorative environments do not tax directed attention resources, thus giving attentional resources an opportunity to recover. ART consists of four components that help separate restorative environments from mere ordinary environments (Kaplan, 1995). Restorative environments should provide a sense of being away, invoke some degree of fascination, provide a sense of being immersed in the environment. and lastly, there should be compatibility between the environment and the visitors' purposes and needs. More recent work by Berman, Jonides, and Kaplan (2008) offer empirical support to the theory, showing that exposure to nature can improve performance on a backwards digitspan task and the Attention Network Task. Other lines of research have considered the effect experiences in nature might have on brain functioning, and thus on how we think, feel and behave. A study by Bratman, Hamilton, Hahn, Daily, and Gross (2015) have shown that a brief experience in nature decreases both self-reported rumination and neural activity in areas in the brain associated with self-focused behavioural withdrawal and rumination.

Yet, research on health benefits has largely dealt with the measurable physiological and psychological effects of exposure to nature and outdoor activities (Bele, 2013; Bischoff, Marcussen, \& Reiten, 2007). Relatively little attention has been 
focused on the subjective experiences individuals have in relation to nature and their own understanding of what it is about nature that promotes health, eventually what it is that contributes to negative affects which can then lead to aversive effects. It is important to delineate, not just the effects of nature on health but also the mechanisms by which such effects materialize. In keeping with this line of thought, patients seeking treatment for mental health issues may themselves be able to shed light on what they experience as causal relationships in their own lives. The present qualitative study was performed at a mental health clinic where the natural environment is an integral part of the facility through proximity, and through a focused use of nature in treatment.

\section{Method}

\section{Design}

The main goal of the study was to examine the lived and experienced qualities and subjectively meaningful phenomena of the human meeting with nature. A phenomenological approach, in line with "Reflective Lifeworld Research", was employed in order to describe the lived world in a way that expands our understanding of human experience (Finlay, 2011). As with Fitzpatrick and Finlay (2009), this study combines a phenomenological lifeworld approach with a transparent thematic analysis process for analysing data. The rationale for this hybrid phenomenological approach is to give a broad account of the entire dataset, rather than a detailed account of specific aspects. This choice was made on the basis that there exists little research on the specific topic of this study and that a broader statement could provide an overview that will possibly be useful for future research. 


\section{Reflexivity}

The present study was partly motivated by the researchers' personal and professional curiosity concerning the effect experiences in nature has on people. The phenomenological attitude involves adopting an open, non-judgmental approach, being curious but at the same time limiting prior assumptions and knowledge (Finlay, 2011). Precautions like conscious awareness and discussions between researchers were taken to bracket this possible influence.

\section{Study Site}

Data collection took place at Viken Center, which is a national institution for residential treatment in mental healthcare located in Bardu Municipality, Troms, Norway. The center is set in beautiful natural surroundings and the use of nature is emphasized in treatment. Architecturally, it was an explicit aim to bring nature into the buildings, to meld the inner with the outer surroundings, with large windows and extensive use of wood and natural materials. Treatment is provided in four different teams: Family team, Existential team, Trauma team and Cognitive team. Diagnostically, patients' presenting problems are generally within the realm of depression, anxiety, and post-traumatic stress disorder. The main treatment takes place within a period of about 9 weeks and may be termed as nature-based therapy (Shalin, Matuszczyk, Ahlborg \& Grahn, 2012). The use of nature in the therapeutic setting involves weekly short-day trips in groups, for example, by foot, snowshoe or canoe. The trips are structured and staff members are leading the sessions. Clients can also be given specific tasks to be carried out in nature, such as finding an object that evokes memories, or with which the patient can personally identify, or is a representation of something important in the patient's life. Patients are also encouraged to use their free time in nature, using provided bicycles and skis, or walking along paths. 


\section{Participants}

Twelve patients voluntarily enrolled in the study: 3 males and 9 females. The age range was 25-60 years. The selection criterion was that participants had been in treatment in one of the four teams at the institution for five weeks or more. This time limit allowed them the possibility to experience the use of nature in the treatment context. Only patients from the Family team and Existential team fulfilled the criterion of five weeks in treatment at the time of data collection.

\section{Interview}

Twelve semi-structured interviews were conducted, lasting from 30 to 60 minutes. The questions in the interview guide were designed to elicit and encourage the patient's description of 1) what they experience as nature, 2) how nature affects them and their mental health, and 3) the importance of nature for their treatment. The questions served as reminders and were followed up with detailed follow up questions where relevant.

\section{Transcription.}

The researchers transcribed the interviews into the software NVivo version 10.1.3 (QSR International, 2014). Transcription was performed with regard to what was spoken, not on how it was spoken (Kvale, 1996). Apart from personal data (name and other identifying information), all verbal information on the tape recordings was transcribed. Citations used in this study were translated from Norwegian to English by prioritizing meaning rather than word-for-word rendition.

\section{Ethical Considerations}

The project was reviewed by the Regional Committee for Medical Research Ethics in Norway (REK No. 2014/1099) and was given exemption from further seeking 
of approval since the aim of the study were not investigate new knowledge about health and disease. Since no direct or indirect identifiable information were collected about participants, the study was also given exemption from notification to the Norwegian Center for Research Data (NSD). However, all participants were submitted written information about the study. Before they signed up to attend they were also informed that they were free to withdraw from the study at any time with no consequences for further treatment. An important consideration was assuring that none of the participants had any previous, present or planned future therapeutic relationship with the researcher who conducted the interview.

\section{Analysis}

Thematic analysis was the method used for identifying, analysing and reporting themes (Braun \& Clarke, 2006). Themes are patterns in a dataset that are important for the description of a phenomenon. Throughout analysis the researchers tried to establish common agreement. The analysis is performed through a process of coding and reencoding in 6 stages to create established and meaningful patterns.

The 6 stages are: familiarizing oneself with the material, generating initial codes, searching for themes, reviewing themes, defining and naming themes, and producing the report. In the first step, the researchers familiarized themselves with the depth and breadth of content through active and repeated readings of all the interviews before generating initial codes. During this phase, every meaningful unit, however small, was encoded to bring out every potential issue in the dataset. Three rounds of coding for each interview was conducted. In this part of the analysis, an effort was made to encode what was said (i.e. semantic approach) and not by how the units could be interpreted (Braun \& Clarke, 2006). This is based on an understanding that language expresses the specific experience, which is the foundation of knowledge that is established in this 
article (Willig, 2008). As codes developed with multiple quote excerpts, the researchers designed descriptions of the individual code. The approach in this part of the analysis is inductive and based as far as possible solely on characteristics of the data. The third, fourth and fifth steps involved analysing and sorting the codes into potential overarching themes, both in NVivo and with mind-mapping technique, refining and designating the final themes (Braun \& Clarke, 2006), where some themes were merged, and others were divided into further themes, and finally defining the essence of each theme. This was done by extracting the statements within each theme that was considered most descriptive for the subject, then summarizing a definition of each theme. The last part of the analysis entailed dissemination of the findings. The story became coherent when all the themes were connected to the study's proposed topics and the overarching research questions.

\section{Results and Discussion}

Thematic analysis resulted in the creation of two main themes: «being human in nature» which included 3 sub-themes "experience of nature", "effects on focus and attention", and "change and the transformative in nature", and «nature, the patient and treatment» with 2 sub-themes "nature as therapy" and "nature and therapy".

\section{Being Human in Nature}

\section{Sub-theme 1: Experience of Nature}

Nature was described as being stable and trustworthy while at the same time always changing and evolving. These paradoxical qualities of constancy and movement were referred to by the participants as being the way things were meant to be. The cyclical essence of nature, for example sunrise and sunset and the tides, was mentioned as aspects that reinforce the experience of nature as being utterly dependable: 
'Even if I don't want to get up in the morning, the morning still meets me, no matter what.'

The experience of nature was referred to as a meeting between the human and the elements. What happens in this meeting was often described in terms of the one part being influenced by the other part: a non-dialogical encounter leaving the human impacted in some way. Some expressed the importance of contrast between their usual state and what they experience in the natural environment. After a day of turmoil, meeting the quiet away from manmade unrest made an impression that was often long lasting. The contrast between one's usual state of being and the unpredictable yet stable natural environs was invariably described as meaningful. The contrast was also described in relation to all the senses, not just the visual or the auditory, but olfactory, tactile (feeling the sun) and to a lesser degree gustatory (tasting the sea air). The essence of nature as being vast conjured feelings that are described variably as being a part of something larger and unknowable, wonder over existence, feeling small in comparison, and humility in its presence:

\footnotetext{
For me it is a reminder that there is something greater than me. That there is something beautiful in the otherwise chaotic system, and that the earth coexists nicely with itself. (...) nature reminds me that there is something greater.
}

Several participants felt a sense of belonging when in natural environments, including a feeling of being an inherent and equal part of nature. Others associated existential thoughts in nature to particular scenery, especially big panoramas, stars or great wildlife. The feeling of belonging was mostly described as positive. However, some experienced it as frightening to feel like an small part of something huge. According to Yalom (1980), man's longing to belong to something larger is a key feature of existential isolation. As one of the four final conditions of life (together with death, 
freedom and meaninglessness), existential isolation is regarded as the tragic recognition that there is an insurmountable chasm between every human and other creatures, and still longing to belong to something bigger. Through this perspective, the participants' experiences may be understood as an expression of exactly this, existential isolation and a universal human longing to belong. At the same time, it may seem as if some participants are experiencing belonging in natural environments, and not longing for belonging. Slåttå and Madsen (2014) have attempted to fuse existential psychology and eco-psychology by adding a fifth final condition. In this perspective, the isolation that the modern human is prone to experience is not understood as an inevitable part of life, but rather a consequence of living in a modern time. Slåttå and Madsen (2014, p. 7, our translation) define this in the following way: 'Man is nature and is born of a mutual relationship with, and dependence on, nature. (...) It is a fundamental dependence framing the human existence, a final and inevitable condition, in other words an existential dependence'. In this line of argument, the feeling of belonging is regarded as man's natural relation to natural environments and is thought to be a healing experience of wholeness, inter-connectedness and belonging which is often sought in therapeutic use of nature (Corazon et al., 2012; Kaplan, 2001; Mayer, Frantz, Bruehlman-Senecal, \& Dolliver, 2009). Indeed, several participants described their dependency on the natural environment as a vital condition for their existence. At the same time, it is important to note that almost half of the participants in our study were participating in existential group therapy at the time, which may have made the participants primed to reflect on existential topics. Yet, existential reflections are commonly reported themes in previous examinations of the perceived therapeutic value of nature (Berger \& Mcleod, 2006; Shalin et al., 2012). 


\section{Sub-theme 2: Effects on Focus and Attention}

Participants reported a number of effects on internal processes (e.g. attention, thoughts and feelings), in relation to others and oneself, that occurred when they were present in nature. The change in attention was described as a shift, e.g. from worrying, to sensory experiences in nature. The participants reported a greater presence in what was happening in the moment, through sensations. Often the sensations in nature were described as 'a pleasure', 'a powerful experience', 'being awake in the body', 'to live in the present' and that 'time stops'. One patient described it as follows:

\footnotetext{
(...) small details and variations were large in a way. Other things became less important; you came a little closer to the elements. It was a very nice experience (...) I felt that time slowed somewhat for us and that small variations that we experienced with birds and everything like that, was sort of the big events.
}

Participants often described the feeling of being in the moment, that time stood still, and the rush of everyday life seemed to slow or dissipate. It could seem as if some participants were experiencing meditative-like states, simply by being in a natural environment, without exercising a meditation discipline, like mindfulness. Such experiences resonate with the ART-framework, where effort has been made to understand the similarities and differences between eastern meditation tradition and attention restoration. In an analysis, Kaplan (2001) proposed that both traditions are concerned with avoiding the depletion of directed attention, thereby allowing the mind to rest and regain its capacity to focus. What separates them may be in what way the individual participates to achieve this. According to restoration theory, this may happen 'passively' through experiencing mild fascination in natural environments. Conversely, meditation practice is a more active approach where one, among other things, seeks to eliminate effortful participation in thought (Kaplan, 2001). Interestingly, a study among undergraduates participating in an outdoor guiding program showed an increase in 
mindfulness scores, even without the practice of meditation (Unsworth, Palicki, \& Lustig, 2016). This, and our findings, seem to be in line with the suggestion from Kaplan (2001) that given an appropriate restorative environment, a relatively unskilled individual could do something approximating meditation, with little mental effort or no meditation training. A study by Lymeus, Lundgren, and Hartig (2016) indicated that the restorative features of natural environments can enhance meditative states, and possibly relieve the attentional strain of conventional mindfulness practice.

Many participants reported that one's degree of openness to nature is a crucial factor. Being able or willing to open up for new experiences, whether through the senses or actively seeking something, influences experience in nature:

'If you are looking for the beautiful, you discover beauty, and if you're seeking something scary, you'll find it'.

Multiple participants believed that openness depends partly on not being overwhelmed by psychopathology. Some said that if they are to benefit from the use of nature as part of therapy, it is a prerequisite not to be too troubled as they then have difficulty focusing their thoughts on anything outside themselves. Others, however, felt that being in nature helped them focus their thinking on other things than themselves.

\section{Sub-theme 3: Change and the Transformative in Nature}

Participants described ways in which they felt being in proximity to nature enabled them to see themselves in different ways than usual, and to react differently. The serenity of being in nature, for example, provided a backdrop that made their usual problems seem less dramatic in comparison which in turn helped them change their perspective and ways of dealing with problems. The change in cognition or thoughts was reported generally as a movement from negative thoughts to more positive ones, or 
that negative thoughts seemed to vanish, while others reported that the thoughts became more clear, easier to sort and that they flowed more freely. This was portrayed as a movement from 'heavy' emotions (sadness, bodily heaviness) to 'lighter' emotions (joy, happiness, excitement, satisfaction, humility). A few participants reported a greater ability to regulate difficult emotions when being outdoors. Others again highlighted the importance of fascinating, moving and unusual experiences to draw the attention away from negative thinking and rumination. Often the realization of being able to experience the lack of negativity had a positive effect that could generalize into other situations. This realization for some, who were often preoccupied by their own negative thoughts and emotions, was a new experience that had transformative qualities in that the experience persisted and permeated other experiences:

'The experiences are of a certain quality, which have the ability to push other things away. Nature has a very potent force on humans, I believe, to make the system relax.'

These perceived changes in self-reflection, and a cognitive shift from negative to more neutral or positive thinking is in line with findings from Attention Restoration Theory (ART) (Kaplan, 1995).

As a contrast to the reported positive change, several participants reported occasions where negative emotions had become overwhelming in nature, and where the general change in emotion is negative. It seems as if exposure to natural environments at times can intensify one's 'dark state of mind', loneliness, or the feeling of being small and unsafe. Negative emotions were described as more likely when alone and immersed in one's inner life, thus unable to be consumed in the natural environment in a constructive way. While it is difficult to know what mechanisms are involved, some different ideas are worth mentioning. The first is the assumption that psychopathology 
is a hindrance to the positive effects of exposure to natural environments, as some participants have reported. However, this assumption could be an attribution of negative change to internal rather than external factors. A study by Roe and Aspinall (2011) may actually give this notion some support. They reported that participants with poor mental health showed more beneficial change in restorative environments, compared to participants with good mental health. A third option is that the relationship between psychopathology and the level of environmental restoration could be bell-shaped. If so, it could indicate that some levels of psychopathology can allow high levels of environmental restoration (no restoration without initial stress), while higher levels of psychopathology may be a hindrance. No known study has investigated the nature of this relationship. Yet another perspective is one of situational factors. Gatersleben and Andrews (2013) have demonstrated that natural places may not always be restorative. Places that are characterized as low in prospect (limited view) and high in refuge (enclosed), like dense woodlands, may even increase levels of stress and attention fatigue, which could have further effects on mood. This could function as an alternative explanation as to why some participants report negative changes in natural environments. Interestingly, a study by Milligan and Bingley (2007) reported that subjects who preferred restorative environments (like woodlands) often made associations with experiences from childhood in similar environments. In this way, what might be a restorative place for some participants, could be a frightening place for others. The variation in preferred environmental surroundings was evident in our interviews, although none of the participants explicitly linked the type of environment to negative changes or experiences of non-restoration. 


\section{Nature, the Patient and Treatment}

\section{Sub-theme 1: Nature as therapy}

'Instead of using drugs, I have used the forest as part of the therapy.'

Nature was described by several as having therapeutic qualities in itself, as bringing out good things in them, as creating an atmosphere of serenity and tranquillity conducive to opening the mind and letting them think and feel differently than they otherwise would have.

Nature was described by some as their medicine, a drug that made the use of psychotropic drugs less necessary. Some described the natural scenery as 'a green prescription drug' or that they needed a 'daily dose'. Several participants reported that they believed they would be using psychotropic drugs had they not had access to nature, while many of the participants also reported a scepticism to using these drugs. One participant described using antidepressants for a period and experienced that life was 'flat', without the highs and lows, something that was experienced as negative. In contrast, the natural scenery was referred to as the participant's alternative solution. Nature was also described by some as 'my therapy session' or 'the strongest therapy for me.' One of the participants described how a difficult period in life was endured and actually dealt with after being made aware of and experiencing the restorative influences that can be found in nature. For some of the patients, nature is described as an important aspect of treatment because it provides a place for unimpeded reflection. They emphasized the importance of an uncomplicated environment when you are in stressful and difficult situations, such as being in treatment. Being in nature and thus away from everyday surroundings also provides an experience of freedom: 
'Somehow I let myself be free when I'm in nature and I'm contemplating something.'

Patients report that the natural scenery is characterized by fewer visual restrictions that can be experienced in the confines of a room or building. Fewer restrictions help the mind to work freely and without interference. One of the patients who had experience with group therapy provided outdoors describes the differences between therapy outside versus inside. The participant described a state of thinking differently and feeling more awake when the therapy took place in nature. Indoor therapies have limitations, represented symbolically by four walls that determine what you can and cannot do.

Several participants also reported that experiences in nature often gave them something that they felt they needed, like positivity, strength or beautiful impressions. The idea that nature is giving the participants something, was for some viewed in conjunction with the idea that nature does not demand anything either. This altruistic aspect of nature was compelling and is emphasized by multiple participants who reported that they experienced nature as being without demands, or inciting problems.

\section{Sub-theme 2: Nature and Therapy}

I feel sometimes that everything we take up [in therapy] is so difficult. And there is so much old stuff that comes up, stuff that you think you have forgotten, and it's so awfully hard. And then I get an urgent need, like "I have to get out, I have to leave, I have to get air" It's just like your body is screaming for it.

Treatment evokes negative memories and difficult thoughts and can be experienced as highly stressful. Several participants described nature as a refuge, an escape and a much-needed pause from treatment. Closeness to nature during treatment is described as refreshing and as a contrast to the intensive therapy. Another participant described how 
the natural scenery viewed through the windows may constitute a necessary pause and respite to what is going on in the therapy room, often making it possible to continue with therapy.

For some patients, elements in nature served as a symbol of properties within their self, which can be used therapeutically:

We went out to find something in nature that described ourselves. And I got a very, very surprising reaction, almost before she [the therapist] had said what the task was, I imagined a large and heavy stone. (...) I could describe the stone in relation to my feelings. That it really should have been much heavier than the one I took indoors. It had a red tint that I related to my own soreness and there were wounds that have not healed.

This participant explained that the situation constituted a new or reversed way to regard nature and consequently to view oneself. Being able to express feelings by means of characteristics in a stone or other inanimate object from nature has therapeutic potential. Similar findings have been reported by Shalin et al. (2012) where the symbolism emerging from experiences in nature has been interpreted as offering models to explain one's own situation. Corazon et al. (2011) suggest that one should introduce metaphors together with activities in nature-based therapy as a way of strengthening the therapeutic outcome. In this perspective, metaphors have a unique ability to help verbalize complex ideas, feelings or experiences. Furthermore, natural environments are enriched when it comes to metaphors about existential issues.

Some of the participants reported that being outdoors with others can change the experience of relational insecurity and distance to others. Some reported that contact with others is experienced as safer or more rewarding in natural environments. The sense of social belonging becomes stronger, social anxiety can lighten and it becomes easier to talk to one another. Some patients told us that periods of silence between 
people often characterized the interaction with others when in nature and is felt as more natural than when experienced in other social situations. This provides for some a feeling that it is easier to be themselves with others, as silence is often a part of social interaction. For one participant, this gives her hope that it is possible to experience good relations in her day to day life:

'I get a feeling of hope that it is possible to have healthy relationships with people, because relationships in nature are a little different than in the city.'

The experience of increased relational security to others in nature is described as a result of the experience of nature as a more informal setting in which differences between people become less apparent. Individuals become more alike when experienced in a common setting, away from other socially defining characteristics and when they are working towards a common goal. Hiking or sitting around a bonfire are examples of goals that individuals can take part in and that can lead to new experiences in a social setting:

There is something different about working physically together towards some basic needs such as creating heat, providing food, sharing food, being a little afraid of the dark in a group, such things that are more primary and basic in life, in contrast to things we do together at work (...) I experience the quality of what we have together outdoors as different because it is more basic and goes into the bone, in a way, of life (...) the raw life, the naked life.

With regards to group therapy processes, these experiences may have a positive effect in facilitating bonds between the patients. Yet, a study regarding restoration in a social context indicated that absence of company in natural environments enhances restoration, as long as safety is not a concern (Staats \& Hartig, 2004). At the same time, no known study has focused on subjects in ongoing mental health treatment, where the findings may be affected by contingency and conversely not influenced by the pitfalls of 
retrospection. Changes in relationship factors may also be valid for the relationship between patients and treatment personnel. Jordan and Marshall (2010) make the argument that therapeutic use of nature may bring more democracy into the therapy process, since the natural space is not controlled or owned by the personnel or the patients. This may allow both the therapist and patient to find different ways of relating to one another within the therapeutic relationship, and perhaps also find different solutions to issues and problems (Jordan, 2014).

\section{Conclusion}

Our findings indicate a complex relationship between nature and mental health. Experiences in nature can promote both positive and negative changes in attention, thoughts and emotions. At the same time, contact with nature can give new perspectives on one's own difficulties and existential conditions. In the context of treatment, nature can be understood as therapy by itself or as a tool or enhancement to the therapy process. Some natural experiences have a symbolic function that can be used in therapy and which can provide models to explain complex inner conditions.

The possible limitations of the study are personal contributions of the authors, in the form of experiences, values and interests, which may have influenced the focus and interpretation of the research. In addition, as part of their recovery, the patients were encouraged to participate in nature-based therapeutic activities which may have influenced the patients' ideas and thoughts about the relationship between human and nature. Despite this, our findings have diverse implications for the application of nature in mental health treatment. First and foremost, our findings implicate the advantages of including environmental surroundings in a treatment regimen, both as an arena and as a therapeutic facilitator. Our findings have also shed some light on the close connection between meditation practices and the experience of meditative-like states in natural 
environments. On the complex subject of negative changes in natural environments, our findings implicate a need for more research in a mental health context. Specifically, the way in which different levels of psychopathology may mediate the restorative effects of natural environments and the nature of this relationship. 


\section{References}

Bele, M. (2013). " I naturen kommer jeg liksom på plass i meg selv": sansende nærvær i naturopplevelser som helsefremmende kontekst i psykisk helsearbeid. Universitetet i Agder/University of Agder.

Berger, R., \& Mcleod, J. (2006). Incorporating nature into therapy: a framework for practice. Journal of Systemic Therapies, 25(2), 80-94.

Berman, M. G., Jonides, J., \& Kaplan, S. (2008). The Cognitive Benefits of Interacting With Nature. Psychological Science, 19(12), 1207-1212.

Berman, M. G., Kross, E., Krpan, K. M., Askren, M. K., Burson, A., Deldin, P. J., . . . Jonides, J. (2012). Interacting with nature improves cognition and affect for individuals with depression. J Affect Disord, 140(3), 300-305. doi:10.1016/j.jad.2012.03.012

Bischoff, A., Marcussen, J. C., \& Reiten, T. (2007). Friluftsliv og helse: en kunnskapsoversikt. [Nature and health: a litterature review].

Bratman, G. N., Hamilton, J. P., Hahn, K. S., Daily, G. C., \& Gross, J. J. (2015). Nature experience reduces rumination and subgenual prefrontal cortex activation. Proc Natl Acad Sci U S A, 112(28), 8567-8572. doi:10.1073/pnas.1510459112

Braun, V., \& Clarke, V. (2006). Using thematic analysis in psychology. Qualitative research in psychology, 3(2), 77-101.

Corazon, S., Schilhab, T. S. S., \& Stigsdotter, U. K. (2011). Developing the therapeutic potential of embodied cognition and metaphors in nature-based therapy: lessons from theory to practice. Journal of Adventure Education \& Outdoor Learning, 11(2), 161-171. doi:10.1080/14729679.2011.633389

Corazon, S., Stigsdotter, U. K., Moeller, M. S., \& Rasmussen, S. M. (2012). Nature as therapist: Integrating permaculture with mindfulness- and acceptance-based therapy in the Danish Healing Forest Garden Nacadia. European Journal of Psychotherapy \& Counselling, 14(4), 335-347. doi:10.1080/13642537.2012.734471

Eikenæs, I., Gude, T., \& Hoffart, A. (2006). Integrated wilderness therapy for avoidant personality disorder. Nordic Journal of Psychiatry, 60(4), 275-281.

Ernst, E., Rand, J. I., \& Stevinson, C. (1998). Complementary therapies for depression: an overview. Archives of General Psychiatry, 55(11), 1026-1032. 
Fernee, C. R., Gabrielsen, L. E., Andersen, A. J., \& Mesel, T. (2015). Therapy in the open air: Introducing wilderness therapy to adolescent mental health services in Scandinavia. Scandinavian Psychologist, 2.

Finlay, L. (2011). Phenomenology for Therapists. Oxford: England: Wiley-Blackwell. Fitzpatrick, N. \& Finlay, L. (2009). "Frustrating disability": The lived experience of coping with the rehabilitation phase following flexor tendon surgery. International Journal of Qualitative Studies on Health and Well-being, 3(3), 143154, doi:10.1080/17482620802130407

Gatersleben, B., \& Andrews, M. (2013). When walking in nature is not restorative-the role of prospect and refuge. Health Place, 20, 91-101. doi:10.1016/j.healthplace.2013.01.001

Johansen, S. G., Wang, C. E. A., Binder, P. E., \& Malt, U. F. (2014). Equine-facilitated body and emotion-oriented psychotherapy designed for adolescents and adults not responding to mainstream treatment: A structured program. Journal of psychotherapy integration, 24(4).

Jordan, M. (2014). Moving beyond counselling and psychotherapy as it currently is taking therapy outside. European Journal of Psychotherapy \& Counselling, 16(4), 361-375. doi:10.1080/13642537.2014.956773

Jordan, M., \& Marshall, H. (2010). Taking counselling and psychotherapy outside: Destruction or enrichment of the therapeutic frame? European Journal of Psychotherapy \& Counselling, 12(4), 345-359. doi:10.1080/13642537.2010.530105

Kaplan, R. (2001). The Nature of the View from Home: Psychological Benefits. Environment and Behavior, 33(4), 507-542. doi:10.1177/00139160121973115

Kaplan, R., \& Kaplan, S. (1989). The experience of nature: A psychological perspective. . Cambridge: Cambridge University Press.

Kaplan, S. (1995). The restorative benefits of nature: toward an integrative framework. Journal of Environmental Psychology, 15, 169-182.

Kvale, S. (1996). InterViews: An Introduction to Qualitative Research Interviewing. Thousand Oaks: Sage Publications.

Lymeus, F., Lundgren, T., \& Hartig, T. (2016). Attentional Effort of Beginning Mindfulness Training Is Offset With Practice Directed Toward Images of Natural Scenery. Environment and Behavior. doi:10.1177/0013916516657390 
Madsen, O. J. (2014). The therapeutic turn : how psychology altered Western culture. London: Routledge.

Martinsen, E. W. (2000). Fysisk aktivitet for sinnets helse. [Physical health and psychological health]. Tidsskrift for den norske lægeforening, 120(25), 30543056.

Mayer, F. S., Frantz, C., Bruehlman-Senecal, E., \& Dolliver, K. (2009). Why Is Nature Beneficial: The Role of Connectedness to Nature. Environment and Behavior, 41(5), 607-643.

Milligan, C., \& Bingley, A. (2007). Restorative places or scary spaces? The impact on woodland on the mental well-beeing of young adults. Health and Place, 13, 799811. doi:0.1016/j.healthplace.2007.01.005

Newnham, E. A., \& Page, A. C. (2010). Bridging the gap between best evidence and best practice in mental health. Clinical psychology review, 30(1), 127-142.

QSR International. (2014). Nvivo.

Revell, S., \& Mcleod, J. (2016). Experiences of therapists who integrate walk and talk into their professional practice. Couns. Psychother. Res., 16, 35-43. doi: 10.1002/capr.12042

Revell, S.,\& Mcleod, J. (2017). Therapists 'experience of walk and talk therapy: A descriptive phenomenological study. European Journal of Psychotherapy \& Counselling, 19:3, 267-289. doi: 10.1080/13642537.2017.1348377

Shalin, E., Matuszczyk, J. V., Ahlborg, G., \& Grahn, P. (2012). How Do Participants in Nature-Based Therapy Experience and Evaluate Their Rehabilitation? Journal of Therapeutic Horticulture, 22(1), 9-22.

Slåttå, L. S., \& Madsen, O. J. (2014). «Jeg svømmer alene»: En økopsykologisk utforskning av de endelige vilkår i eksistensiell psykoterapi [«I swim alone» an ecopsychological exploration of the final conditions in existential psychotherapy]. Scandinavian Psychologist, 1(9). doi:http://dx.doi.org/10.15714/scandpsychol.1.e9

Stigsdotter, U. K., Palsdottir, A. M., Burls, A., Chermaz, A., Ferrini, F., \& Grahn, P. (2011). Nature-Based Therapeutic Interventions. In K. Nilsson, M. Sangster, C. Gallis, T. Hartig, S. de Vries, K. Seeland, \& J. Schipperijn (Eds.), Forests, Trees and Human Health (pp. 309-342). London: Springer. 
Staats, H., \& Hartig, T. (2004). Alone or with a friend: A social context for psychological restoration and environmental preferences. Journal of Environmental Psychology, 24(2), 199-211. doi:10.1016/j.jenvp.2003.12.005

Unsworth, S., Palicki, S.-K., \& Lustig, J. (2016). The Impact of Mindful Meditation in Nature on Self-Nature Interconnectedness. Mindfulness, 7(5), 1052-1060. doi:10.1007/s12671-016-0542-8

Willig, C. (2008). Introducing Qualitative Research in Psychology (2 ed.). Maidenhead: Open University Press.

Wilson, E. O. (1984). Biophilia. Cambridge: Harvard University Press.

Yalom, I. D. (1980). Existential Psychotherapy. New York: Basic. 